\section{Public Health Genomics}

Public Health Genomics 2011;14:178-189

DOI: $\underline{10.1159 / 000324703}$
Received: April 27, 2010

Accepted after revision: January 26, 2011 Published online: April 2, 2011

\title{
Interest in Genetic Testing for Modest Changes in Breast Cancer Risk: Implications for SNP Testing
}

\author{
K.D. Graves ${ }^{a}$ B.N.Peshkin ${ }^{a} \quad$ G. Luta ${ }^{b}$ W. Tuong ${ }^{a}$ M.D. Schwartz ${ }^{a}$ \\ a Department of Oncology and The Jess and Mildred Fisher Center for Familial Cancer Research, \\ Lombardi Comprehensive Cancer Center, and ${ }^{b}$ Department of Biostatistics, Bioinformatics, and \\ Biomathematics, Georgetown University, Washington, D.C., USA
}

\section{Key Words}

Breast cancer risk · Genetic testing - Interest - Modest risk changes $\cdot$ Public health genomics $\cdot$ Scenario-based research $\cdot$ SNP testing

\begin{abstract}
Background: Advances in genomics may eventually lead to 'personalized genetic medicine,' yet the clinical utility of predictive testing for modest changes in risk is unclear. We explored interest in genetic testing for genes related to modest changes in breast cancer risk in women at moderate to high risk for breast cancer. Methods: Women ( $n=105)$ with a negative breast biopsy and $\geq 1$ relative with breast or ovarian cancer completed telephone surveys. We measured demographic and psychosocial variables and, following presentation of hypothetical scenarios of genetic tests for lower-penetrance breast cancer gene mutations, assessed interest in willingness to pay for and comprehension of test results. We used logistic regression models with generalized estimating equations to evaluate combinations of risk level, cost and behavioral modifiers. Results: Many women (77\%) reported 'definite' interest in genetic testing, with greater interest in tests that conveyed more risk and cost less. Behavioral modifiers of risk (taking a vitamin; diet/exercise), having a regular physician, greater perceived benefits of genetic testing, and greater cancer worry also influenced interest. Most partici-
\end{abstract}

pants $(63 \%)$ did not understand relative vs. absolute risk. Women with less understanding reported more cancer worry and greater willingness to pay for testing. Conclusion: Interest in genetic testing for mutations related to modest changes in risk was high, modified by both test and psychosocial factors. Findings highlight the need for education about benefits and risks of testing for mutations that convey modest changes in risk, particularly given the current lack of clinical validity/utility and availability of direct-to-consumer genetic testing.

Copyright $\odot 2011$ S. Karger AG, Basel

\section{Introduction}

Wide genetic variation exists in the human genome, and the most common type of genetic sequence variation is called the single nucleotide polymorphism (SNP). SNPs account for about $90 \%$ of all human genetic variation and likely contribute to the multifactorial etiology of common cancers and other common diseases [1]. Unlike mutations in high-penetrance cancer susceptibility genes (e.g. BRCA1/2) that convey large increases in cancer risk

Portions of this paper were presented at the American Society of Preventive Oncology Meeting, March 2009, Tampa, Fla., USA.

\section{KARGER}

Fax +41613061234

E-Mail karger@karger.ch

www.karger.com (c) 2011 S. Karger AG, Basel

Accessible online at: www.karger.com/phg
Kristi D. Graves

Cancer Control Program, Lombardi Comprehensive Cancer Center

3300 Whitehaven Street, NW, Suite 4100

Washington, DC 20007 (USA)

Tel. +1 202687 1591, E-Mail kdg9@georgetown.edu 
for a small number of people, cancer SNPs convey smaller risks for a much larger number of people. Thus, SNPs may be characterized as low to moderate penetrant gene mutations. Advances in genomics are laying the groundwork for 'personalized genetic medicine' - particularly pharmacogenomics - or the study of how genetic variation impacts drug effects [2]. The clinical utility of other aspects of personalized genetic medicine, such as predictive SNP testing, is under debate [3-5]. Predictive SNP testing involves characterizing individuals' risk for disease based on common genetic polymorphisms. Recent commentaries argue that investigating genetic variants for common disease may not yield clinically useful information, given modest increases in risk conveyed by common variants and questions about whether the sheer number of candidate genes can lead to biologically useful information [3]. In contrast, others have suggested that even small increases in 'predictive power' can help guide clinically-relevant prevention efforts [4] or that knowledge of gene variants related to disease risk may impact health behavior [6], although controlled studies have not addressed these issues.

Despite the current debate around the clinical validity and utility of predictive SNP testing, such testing is commercially available and marketed directly to consumers. Over the past several years, access to genetic analysis and testing via Internet has significantly expanded. Over 100 companies offer direct-to-consumer (DTC) genetic testing services, including DTC testing for ancestry, physical and behavioral traits, and health-related conditions [7]. Indeed, several companies offer bundled or multiplex testing for dozens of health conditions (e.g. 23andMe ${ }^{\circledR}$, Navigenics ${ }^{\circledR}$ or deCODEme ${ }^{\circledR}$ ) [8-10]. The emergence of DTC testing has heightened concerns about the limitations of SNP testing. These limitations include the questionable clinical validity and lack of clinical utility for DTC genetic testing [11]. Additional concerns include the unknown ethical, legal, social, psychological, and behavioral impacts of this testing $[5,7,12]$. For example, we do not know whether or how people understand or use information obtained from DTC SNP testing, if people seeking SNP testing understand complex issues such as peiotropy or implications for family members or if test seekers recognize existing legal protections against genetic discrimination. These concerns have led to efforts to promote regulatory oversight of genetic testing advertisements [7, 11, 13], and professional organizations have issued policy statements about DTC genetic testing [14].

As the number of DTC genetic testing companies proliferates and the financial cost of testing decreases, avail- ability and consumer demand will likely increase. Despite the active marketing of these tests, studies have only recently begun exploring consumer interest in, understanding of, uptake and responses to SNP testing for a variety of health conditions [6, 15-17]. Beyond the risks and limitations of DTC SNP testing, a fundamental question is whether and to what extent consumers are interested in learning about the small increases in risk generally conveyed by such testing. Thus, to inform subsequent research in the translation of genomic information, we sought to learn about interest in genetic testing for small to modest changes in genetic risk for breast cancer and investigate individual and genetic-test related factors that may influence interest within a diverse sample of women at moderate to high risk of breast cancer.

We were guided in this research by the ACCE model (analytic validity, clinical validity, clinical utility and ethical, legal and social implications) of Khoury et al. [18]. This ACCE model provides a systematic framework for the translation of genomic testing, defining a sequence of research and clinical steps needed prior to the clinical translation of testing. Specifically, research must evaluate the validity, utility, and ethical, legal and social implications (ELSI) of a test prior to wide-scale translation [1820]. Whether predictive genetic testing for small to modest changes in risk for common chronic diseases is clinically useful remains an open question. Central to the ACCE framework is the need to determine how best to educate the public about the clinical utility of genomic tests. For genomic information to be used appropriately, we must learn whether and how people understand modest genetic changes in risk for common diseases, factors that influence interest in testing and how best to convey risks and benefits of such testing to promote informed decisionmaking [21]. To further initiate translational research efforts in the area of personalized medicine and learn more about potential targets for genetic and genomic education, we investigated women's interest in and understanding of genetic testing for modest changes in breast cancer risk.

\section{Subjects and Methods}

\section{Participants}

Participants were women $(\mathrm{n}=105)$ who were 18 years of age or older, had at least one first or second degree relative with breast or ovarian cancer, had a personal history of having a negative breast biopsy, and were able to understand English and provide informed consent. We chose to focus on women with a family history of breast cancer in order to evaluate interest in SNP testing among women at moderately increased risk for breast cancer. Women with a prior history of breast cancer but who subsequent- 
ly underwent a recent negative breast biopsy were also eligible $(\mathrm{n}=24)$. We included these women to evaluate whether a personal history of the disease impacted interest in genetic testing for modest changes in breast cancer risk. Several women $(n=19)$ had a $10 \%$ or greater likelihood of carrying a deleterious $B R C A 1 / 2 \mathrm{mu}-$ tation based on standard quantitative models [22, 23]. We used mutation carrier probability as assessed by these models as a proxy for risk for developing breast cancer.

\section{Procedures}

Clinic and research staff identified potential participants through an IRB-approved review of clinic records at Ourisman Breast Cancer Center at Lombardi Comprehensive Cancer Center and the Center for Breast Health at Washington Cancer Institute, Washington Hospital Center. Potential participants included women who had at least one first or second degree family member with breast or ovarian cancer and/or had a documented negative breast biopsy $(n=343)$. We mailed potentially eligible women a letter from their physician describing the study and inviting participation. A member of the study staff then called women who did not decline further contact to verify eligibility and, if eligible, schedule a $30 \mathrm{~min}$ telephone interview.

\section{Predictor Variables}

Sociodemographics. We assessed age, race, marital status, education, employment status, insurance status, religion, and household income.

Clinical Information. Participants self-reported family cancer history, personal breast cancer history, timing of their most recent breast biopsy, whether they had a regular physician, and prior genetic testing in the family.

Perceived Risk. We measured perceived risk with 3 items used in previous research $[24,25]$. We obtained an absolute estimate of perceived risk through responses on a 5-point Likert scale ('not at all' to 'definitely') to the question, 'In your opinion, how likely is it that you will develop breast cancer (again)?’ To assess comparative risk, we asked participants, 'In your opinion, compared to other women your age, what are your chances of getting breast cancer (again)?' Participants responded on a 5-point Likert scale ('much lower' to 'much higher') [25]. For numeric risk, we asked participants to rate their likelihood of developing breast cancer on a scale from 0 ('definitely will not get breast cancer (again)') to 100 ('definitely will get breast cancer (again)'). Items were not combined into scales.

Cancer Worry. We measured cancer worry with a single item asking women how often they worried about getting breast cancer in the past month. Responses were made on a 4-point Likert scale ('not at all or rarely' to 'a lot') [26].

Genetics Knowledge. We used a 13-item genetic knowledge questionnaire based on the scale developed by Thompson et al. [27]. Response options were 'true', 'false', or 'don't know.' Sample items included ' $50 \%$ of inherited genetic information (about breast cancer risk) is passed down from a person's mother', and 'There is more than one gene that can increase the risk of breast cancer.' We created a total knowledge score by summing correct responses. Of note, although the psychometrically-sound knowledge measure we used was developed to assess knowledge of genetics related to major gene mutations like $B R C A 1 / 2$, the majority of items were related to general genetic concepts, and none specifically mentioned the BRCA1/2 genes. As such, we opted to use a validated measure of breast cancer genetics knowledge rather than develop a de novo scale of knowledge about genomics, genetic testing for low-penetrance genes and breast cancer risk.

Genetic Testing Attitudes. We measured perceived benefits and barriers to genetic testing for breast cancer risk using an existing 13-item, 5-point Likert scale ('strongly disagree' to 'strongly agree') measure [27]. Sample items from the benefits subscale ( $n=5$ items) include, 'Knowing whether I carry the gene would increase my sense of personal control' and from the barriers subscale ( $\mathrm{n}=8$ items) include 'If I were found to carry the gene, it would jeopardize my insurance coverage or lead to problems with my employers.' As with our assessment of genetic knowledge, we chose to use a validated measure of attitudes about testing for the $B R C A 1 / 2$ major gene mutations rather than develop our own scale of attitudes toward genetic testing for mutations of low penetrance for breast cancer risk.

\section{Genetic Testing Scenarios}

To evaluate factors associated with interest in genetic testing for modest changes in risk, we developed a series of hypothetical scenarios in which we systematically varied the following factors: (1) the level of risk conveyed by the test result, (2) the cost of the test, and (3) whether the risk conveyed by the test could be modified by behavior (see Appendix for a sample scenario). All women received the same scenarios presented in the same order.

Level of Risk. Across the 3 scenarios, we varied level of risk conveyed by the hypothetical genetic tests: $25 \%$ increase in relative risk, $75 \%$ increase in relative risk and $25 \%$ decrease in relative risk. We presented the $25 \%$ increase-risk scenario first, followed by the $75 \%$ increase-risk scenario and then the 25\% decrease-risk scenario.

Cost of the Test and Willingness to Pay. After presenting each risk scenario, we asked women if they would be interested in having the test if the test was free. Next, we asked an open-ended question, 'How much would you pay for this test?' We then asked women if they would be willing to have the test if it costs USD 150 or USD 1,500. Participants responded to the free, USD 150 and USD 1,500 items on a 4-point Likert scale. If a participant responded that she had no interest in testing for any individual item within a scenario, then the interviewer proceeded to the next scenario (see Appendix).

Behavioral Modifiers of Risk. Following assessment of interest in the test, we presented 2 potential behavioral risk modifiers to see whether these behavioral modifiers influenced interest in testing. We asked women, 'How interested would you be in taking this test if there was evidence that taking a vitamin supplement once a day would reduce your risk from $15 \%$ back to the average risk of $12 \%$ ?' We also asked, 'How interested would you be in having the test if there was evidence that exercising regularly and eating a healthy diet would reduce your risk from $15 \%$ back to the average lifetime risk of $12 \%$ ?' These 2 behavioral modification variations were followed by the 3 cost questions noted above (free, USD 150, USD 1,500).

\section{Outcome Variables}

Interest in Genetic Testing. As noted, we assessed interest in having a genetic test for modest changes in breast cancer risk within each of the scenarios (see Appendix). Following each of the 3 risk scenarios (25\% increase in risk, $75 \%$ increase in risk, and $25 \%$ decrease in risk), we asked participants, 'Would you have this test if it was offered free of charge?' with responses made on a 
4-point Likert scale ( 1 = You would definitely not have the test to 4 = You would definitely have the test). This question was then repeated for each cost variation (USD 150 and USD 1,500) and each behavioral modifier (taking a daily vitamin, exercising regularly and eating a healthy diet). For analyses, we created a dichotomous score of interest in genetic testing. If a participant responded they would 'definitely not' or 'probably not' have the test, we coded interest as 0 . Responses of 'probably' or 'definitely' were coded as 1 . We did not ask the behavioral modifier questions following the $25 \%$ decreased-risk scenario, as behavior change to reduce risk would not be salient in the context of risk already below that of the average person.

Understanding of Risk Information. After each scenario, we asked participants to compare their perceived risk if they tested positive for the hypothetical breast cancer SNP to the risk of the average woman. For example, for the $25 \%$ increase-risk scenario, we asked, 'What does it mean to you to hear that the test could tell you that your breast cancer risk is increased by $25 \%$, meaning a $15 \%$ risk compared to the average woman's risk of $12 \%$ ? To you, does this mean that if you tested positive your risk of getting breast cancer would be ...' Participants then responded using a 5 -point Likert scale, with responses ranging from 'Much higher than the average woman's risk' to 'Much lower than the average woman's risk.' We also created dichotomous outcomes for each understanding of risk information item. Specifically, we coded responses in which participants chose either the correct answer or the answer within one Likert-scale category of the correct response as 1 . Other responses were coded as 0 .

\section{Statistical Analyses}

We generated descriptive statistics to characterize the sociodemographics, psychosocial and medical variables and family history of the sample (table 1). We also generated descriptive statistics to characterize the level of interest in genetic testing within and across the various scenarios (table 2). To investigate statistically significant differences in interest in genetic testing within and across scenarios, we used logistic regression models with generalized estimating equations (GEE) using a working exchangeable correlation structure. We used this approach to analyze the correlated binary data as a way to account for the correlations among responses by the same participant $[28,29]$. We treated the dichotomized responses from each person (interested vs. not interested in genetic testing) as a cluster of size 21, corresponding to the individual items each participant was asked within each scenario. We evaluated the presence of pairwise interactions among risk level, test cost (free, USD 150, USD 1,500) and behavior (taking a multivitamin, exercising and eating healthy). We identified covariates that were statistically significantly associated with genetic testing interest by including variables one at a time into separate logistic regression models with GEE. In subsequent models for evaluating predictors of genetic testing interest by risk level, test cost and behavior, we included all covariates with $\mathrm{p}<0.10$. We calculated unadjusted and covariate adjusted odds ratios (ORs) and corresponding 95\% confidence intervals using the logistic regression models with GEE. For the statistical analyses involving willingness to pay for genetic testing and understanding of risk information, we used t-tests and linear regression analyses to compare groups of interest with respect to continuous measures. We fitted the logistic regression models with GEE using PROC GENMOD from SAS 9.2 (SAS Institute, Cary, N.C., USA).
Table 1. Demographic characteristics of the sample $(\mathrm{n}=105)$

\begin{tabular}{|c|c|}
\hline Characteristics & $\mathrm{n}(\%)$ \\
\hline \multicolumn{2}{|l|}{ Age } \\
\hline$\geq 50$ & $44(41.9)$ \\
\hline$<50$ & $61(58.1)$ \\
\hline \multicolumn{2}{|l|}{ Breast cancer affected status } \\
\hline Affected with breast cancer & $24(22.6)$ \\
\hline Unaffected with breast cancer & $81(77.4)$ \\
\hline \multicolumn{2}{|l|}{ Risk status } \\
\hline$\leq 10 \%$ likelihood of carrying $B R C A 1 / 2$ mutation & $19(18.1)$ \\
\hline$>10 \%$ likelihood of carrying BRCA1/2 mutation & $86(81.9)$ \\
\hline \multicolumn{2}{|l|}{ Marital status } \\
\hline Married & $57(54.3)$ \\
\hline Unmarried & $48(45.7)$ \\
\hline \multicolumn{2}{|l|}{ Education } \\
\hline Some college/degree & $67(63.8)$ \\
\hline No college & $38(36.2)$ \\
\hline \multicolumn{2}{|l|}{ Employed } \\
\hline Full time & $63(60.6)$ \\
\hline$<$ Full time & $41(39.4)$ \\
\hline \multicolumn{2}{|l|}{ Annual income } \\
\hline$\geq 75,000$ & $64(60.9)$ \\
\hline$<75,000$ & $41(39.1)$ \\
\hline \multicolumn{2}{|l|}{ Race } \\
\hline White & $71(67.6)$ \\
\hline African American & $28(26.7)$ \\
\hline Other & $6(5.7)$ \\
\hline \multicolumn{2}{|l|}{ Regular physician } \\
\hline Yes & $94(89.5)$ \\
\hline No & $11(10.5)$ \\
\hline \multicolumn{2}{|l|}{ Insured } \\
\hline Yes & $102(97.1)$ \\
\hline No & $3(2.9)$ \\
\hline \multicolumn{2}{|l|}{ Cancer worry } \\
\hline High & $45(42.9)$ \\
\hline Low & $60(57.1)$ \\
\hline \multicolumn{2}{|l|}{ Perceived benefits of testing } \\
\hline High & $53(50.5)$ \\
\hline Low & $52(49.5)$ \\
\hline
\end{tabular}

Affected $=$ Affected with breast cancer.

\section{Results}

\section{Sample Characteristics}

Of the 343 invitation letters we mailed to potentially eligible women, 93 (27\%) were ineligible, 26 had incorrect contact information $(7.6 \%)$ and $3(<1 \%)$ were deceased. Of the 221 potentially eligible women, 96 (43\%) were unreachable with up to 10 telephone calls. Of the 125 women who were eligible and reachable, 105 (84\%) completed the telephone interview and 20 declined participation. 
Table 2. Frequency of interest in SNP testing by combinations of risk level, cost and behavioral modifiers

\begin{tabular}{|c|c|c|c|c|}
\hline \multirow[t]{2}{*}{ Behavioral modifier } & \multirow[t]{2}{*}{ Cost } & \multirow{2}{*}{$\frac{25 \% \text { increase SNP }}{\text { interested, } \mathrm{n}(\%)}$} & \multirow{2}{*}{$\frac{75 \% \text { increase SNP }}{\text { interested, } \mathrm{n}(\%)}$} & \multirow{2}{*}{$\frac{25 \% \text { decrease SNP }}{\text { interested, n (\%) }}$} \\
\hline & & & & \\
\hline \multirow[t]{3}{*}{ None } & None & $93(87.7)$ & $96(93.3)$ & $69(65.1)$ \\
\hline & USD 150 & $68(64.8)$ & $85(80.1)$ & $53(50.0)$ \\
\hline & USD 1,500 & $21(20.0)$ & $41(39.4)$ & $23(21.7)$ \\
\hline \multirow[t]{3}{*}{ Vitamin } & None & $90(84.9)$ & $88(83.8)$ & \\
\hline & USD 150 & $75(71.4)$ & $77(73.3)$ & \\
\hline & USD 1,500 & $25(23.8)$ & $35(33.3)$ & \\
\hline \multirow[t]{3}{*}{ Exercise/diet } & None & $79(75.2)$ & $84(80.0)$ & \\
\hline & USD 150 & $61(58.6)$ & $72(68.6)$ & \\
\hline & USD 1,500 & $22(21.1)$ & $33(31.4)$ & \\
\hline
\end{tabular}

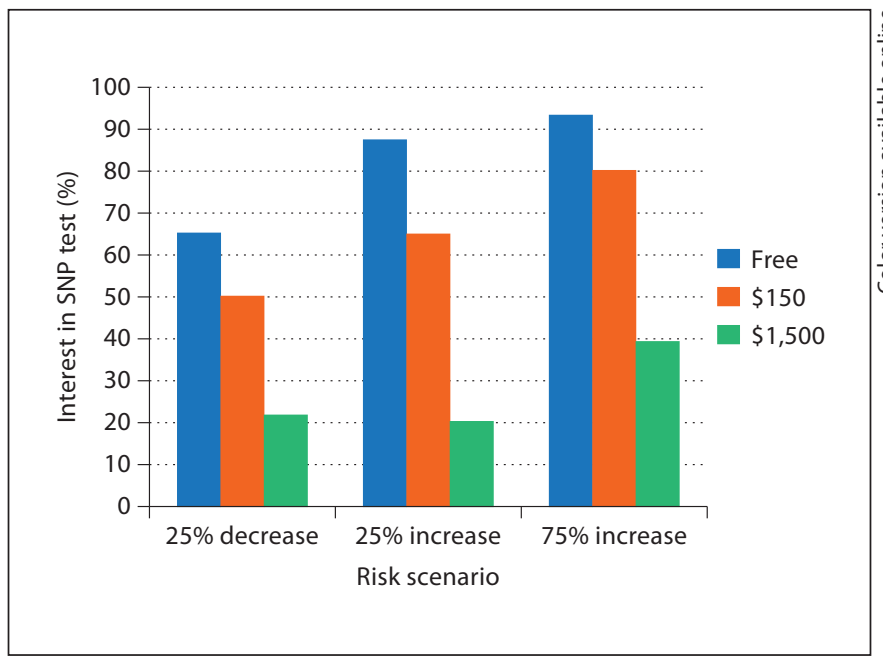

Fig. 1. Interest in SNP testing by risk level and cost.

Approximately one-quarter of our sample (26.4\%) were African American, and, on average, participants were 53.1 years old (SD 12.8 years; range 20-82 years). Slightly less than one-fifth of the sample $(\mathrm{n}=19 ; 18.1 \%)$ was at $10 \%$ or greater risk of carrying a deleterious $B R C A 1 / 2$ mutation. Of these 19 women, 12 were unaffected with breast cancer and thus considered to be at high risk for developing breast cancer. Just under one-quarter (22.6\%) of the sample had a personal history of breast cancer (table 1).

Interest in Genetic Testing for Modest Changes in Risk

Interest in genetic testing for modest changes in genetic risk for breast cancer was high across the 3 risk lev-

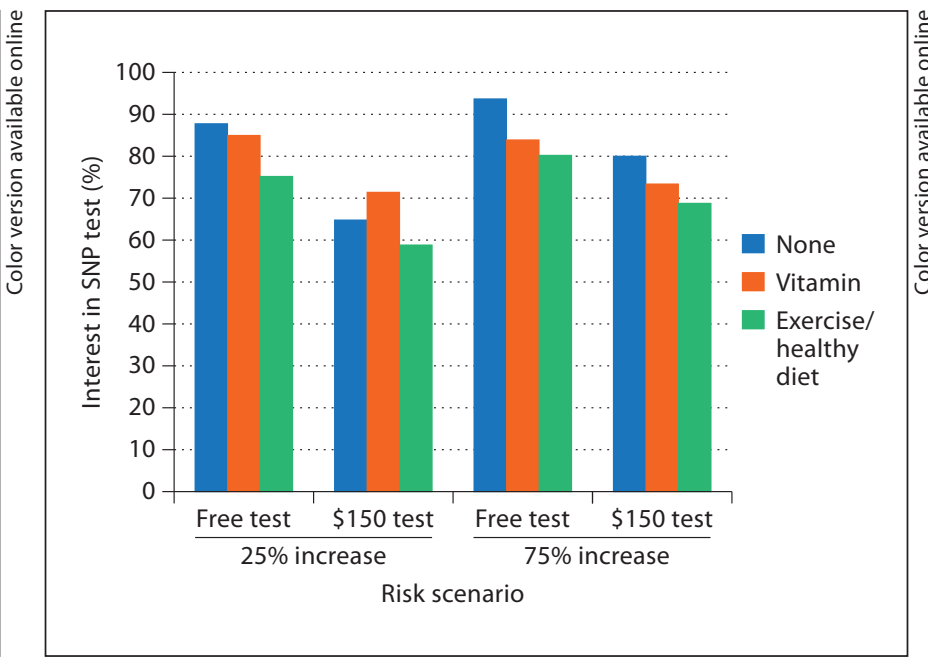

Fig. 2. Interest in SNP testing by behavioral modifier for risk level.

els, with interest increasing as the level of risk conveyed by the test increased (table 2). As displayed in figure 1, interest in testing decreased as cost increased; however, within all 3 cost levels, interest in testing increased as risk level conveyed by the test increased. As displayed in figure 2, we show examples at the free and USD 150 cost levels of how the hypothetical behavioral modifiers decreased interest in testing across the $25 \%$ increased and $75 \%$ increased-risk scenarios. Of note, interest did not decrease as much for the $75 \%$ increased-risk scenario as for the $25 \%$ increased-risk scenario with presentation of the behavioral modifiers. 
Table 3. Adjusted ${ }^{\mathrm{a}}$ associations between combinations of risk level and test cost with interest in SNP testing

\begin{tabular}{llll}
\hline Cost & $\begin{array}{l}\text { 25\% increase SNP } \\
\text { OR }(95 \% \mathrm{CI})\end{array}$ & $\begin{array}{l}75 \% \text { increase SNP } \\
\text { OR }(95 \% \mathrm{CI})\end{array}$ & $\begin{array}{l}\text { 25\% decrease SNP } \\
\text { OR }(95 \% \mathrm{CI})\end{array}$ \\
\hline None & $\mathbf{1 . 0 0}$ & $2.17(0.96,4.9)^{\#}$ & $0.22(0.10,0.47)^{* * *}$ \\
USD 150 & $0.21(0.11,0.41)^{* * *}$ & $0.56(0.27,1.17)$ & $0.12(0.05,0.26)^{* * *}$ \\
USD 1,500 & $0.03(0.01,0.06)^{* * *}$ & $0.07(0.03,0.16)^{* * *}$ & $0.03(0.01,0.07)^{* * *}$ \\
\hline
\end{tabular}

\footnotetext{
a Adjusted for having a regular physician, perceived benefits of genetic testing and cancer worry.

${ }^{\#} \mathrm{p}<0.10,{ }^{* * *} \mathrm{p}<0.0001$.

The bolded OR of 1.0 indicates that the $25 \%$ increase risk SNP free-cost scenario served as the reference for the other comparisons.
}

\section{Bivariate Analyses}

We used logistic regression models with GEE to evaluate associations between our covariates and the dichotomous genetic testing interest outcomes. Greater interest in genetic testing was expressed by individuals who reported having a regular physician $(p=0.0002)$, higher perceived benefits of genetic testing $(\mathrm{p}=0.03)$, and higher cancer worry $(\mathrm{p}=0.08)$. We adjusted for these variables in all subsequent models. None of the remaining covariates were statistically significantly associated with genetic testing interest.

\section{Multivariate Analyses}

Our preliminary analyses identified statistically significant pairwise interactions between level of risk, cost of the test and behavioral modifiers (all p $<0.001$ ), indicating that the association of each one of these 3 variables with genetic testing interest depends on the level of the other 2 variables (e.g. the association between risk level and testing interest depends on the cost and behavioral modifiers). Thus, to evaluate whether test-related factors (level of risk conveyed by the genetic test result, cost) and behavioral modifiers (taking a vitamin, diet and exercise) influenced interest in genetic testing, we used logistic regression models with GEE and adjusted for the confounders with significant associations with interest in genetic testing (regular physician, perceived benefits and cancer worry).

Impact of Test Characteristics on Genetic Testing Interest. Table 3 displays our analysis of the impact of test characteristics (test cost and level of risk conveyed by the test) on testing interest. In these analyses, the free test at $25 \%$ increased risk served as the reference level. The only scenario that resulted in increased interest compared to the reference was the $75 \%$ increased risk, free testing con- dition. Across the remaining scenarios, interest in testing decreased as the cost of the test increased. These differences were statistically significant with one exception: interest in genetic testing for the $75 \%$ increased-risk scenario at the cost of USD 150 did not differ from the free $25 \%$ increased-risk scenario. Overall, participants were more interested in genetic testing when the test was less expensive and conveyed higher cancer risk.

Impact of Behavioral Modifiers on Genetic Testing Interest. Table 4 displays our analyses of the impact of behavioral risk modifiers on interest in genetic testing for genes related to modest changes in breast cancer risk. These analyses include only the $25 \%$ and $75 \%$ increasedrisk scenarios. Specifically, women were asked about interest in genetic testing if they could reduce any increased gene-based risk back to average risk by either taking a vitamin or engaging in exercise and a healthy diet. With one exception, women's interest in genetic testing for modest changes in breast cancer risk was statistically significantly lowered with presentation of the behavioral modifiers. Only in the free testing 25\% increased-risk scenario did interest in testing with the vitamin modifier not differ from the scenario without any modifier. For all other items, women reported statistically significantly less interest in genetic testing if they were presented with a situation in which they could change their behavior to reduce any gene-related increase in risk back to average. When we compared whether genetic testing interest differed between the vitamin and exercise/healthy diet scenarios within the same risk level, we found that for the $25 \%$ increased-risk scenario, women were less interested in testing if they would need to exercise/eat a healthy diet vs. taking a daily vitamin $(\mathrm{OR}=0.51, \mathrm{p}=0.012)$ to return risk to average when the test was free. There was no statistically significant difference in genetic testing interest 
Table 4. Adjusted $^{\mathrm{a}}$ associations between combinations of behavior and cost with interest in SNP testing separately for each increased risk level scenario

\begin{tabular}{llll}
\hline Behavior & Cost & $\begin{array}{l}\text { 25\% increase SNP } \\
\text { OR }(95 \% \mathrm{CI})\end{array}$ & $\begin{array}{l}\text { 75\% increase SNP } \\
\text { OR }(95 \% \mathrm{CI})\end{array}$ \\
\hline None & None & $\mathbf{1 . 0 0}^{\mathrm{b}}$ & $\mathbf{1 . 0 0}^{\mathrm{c}}$ \\
\hline Vitamin & None & $0.76(0.36,1.63)$ & $0.32(0.13,0.79)^{*}$ \\
& USD 150 & $0.30(0.13,0.65)^{* *}$ & $0.16(0.06,0.41)^{* * *}$ \\
Exercise and & USD 1,500 & $0.03(0.01,0.08)^{* * *}$ & $0.02(0.01,0.07)^{* * *}$ \\
healthy diet & None & $0.39(0.20,0.75)^{* *}$ & $0.24(0.10,0.59)^{* *}$ \\
& USD 150 & $0.16(0.08,0.34)^{* * *}$ & $0.12(0.05,0.33)^{* * *}$ \\
& USD 1,500 & $0.03(0.01,0.07)^{* * *}$ & $0.02(0.01,0.07)^{* * *}$ \\
\hline
\end{tabular}

\footnotetext{
a Analyses adjusted for having a regular physician, perceived benefits of genetic testing and cancer worry. b The 25\% increase SNP free scenario served as a reference for the comparisons made to the other $25 \%$ increase SNP scenarios. ${ }^{c}$ The $75 \%$ increase SNP free scenario served as a reference for the comparisons made to the other 75\% increase SNP scenarios.

${ }^{*} \mathrm{p}<0.05,{ }^{* *} \mathrm{p}<0.001,{ }^{* *} \mathrm{p}<0.0001$.
}

between the behavioral modifiers in the $75 \%$ increasedrisk scenario for a free test. Similar to the nonmodified scenarios, testing interest decreased within the behaviorally modified scenarios as the cost of the test increased.

Willingness to Pay for Genetic Testing for Modest Changes in Breast Cancer Risk. The majority of women were willing to pay for genetic test results. On average, women were willing to pay USD 197 for the 25\% increased-risk gene test, USD 342 for the $75 \%$ increasedrisk gene test, and USD 145 for the 25\% decreased-risk gene test. The number of women unwilling to pay any amount decreased as the risk conveyed by the genetic test increased: $38 \%$ were unwilling to pay any money for the SNP test that indicated $25 \%$ decreased risk, $17 \%$ for the $25 \%$ increased-risk test and 15\% for the $75 \%$ increasedrisk test. Higher levels of cancer worry were associated with willingness to pay increasing amounts of money for genetic test across all risk scenarios $(\mathrm{p}<0.05)$.

Understanding of Risk Information. To evaluate participants' understanding of the risk information presented in each scenario, we asked them to compare their perceived risk of breast cancer if they tested positive for the hypothetical breast cancer gene to the risk of an average woman. Women were unclear about how to interpret the magnitude of the degree of risk conveyed by the genetic test result. For example, about one-fifth of the sample $(21.9 \%)$ indicated that a $25 \%$ increase in risk over average risk conveyed a likelihood of a future cancer diagnosis that was 'much higher' than the average woman. A few women $(5.7 \%)$ reported that risk was higher for a woman who tested positive for a genetic test that indicated a $25 \%$ decreased risk compared to the average woman's risk of breast cancer. We also evaluated whether participants who understood risk information differed from participants who did not understand risk information on interest in genetic testing. Understanding of risk information was not related to interest in testing. Greater understanding of risk information in the $25 \%$ increased risk scenario was related to less cancer worry $\left(\mathrm{t}_{(\mathrm{n}=105)}=2.87, \mathrm{p}=\right.$ 0.005). Moreover, less understanding of risk information was associated with willingness to pay more money for a genetic test for the $75 \%$ increased risk scenario $\left(\mathrm{t}_{(\mathrm{n}=105)}=\right.$ $4.15, \mathrm{p}<0.001)$, with a trend for the $25 \%$ increased risk scenario $\left(\mathrm{t}_{(\mathrm{n}=105)}=1.90, \mathrm{p}=0.07\right)$.

\section{Discussion}

Interest in genetic testing for hypothetical gene mutations related to modest changes in breast cancer risk was high in our diverse sample of women at moderate to high lifetime risk of developing the illness, as three-fourths of the sample (77\%) indicated 'definite' interest in testing in at least one or more of our scenarios. The present study is among the first to document interest in testing for gene mutations related to modest changes in genetic risk based on varying levels of risk, cost, and potential behavioral modification. Our sample included women at greater risk 
for breast cancer than women in the general population, and, thus, our participants may be more invested in obtaining genetic risk information. The high level of overall interest in genetic testing for modest increases in breast cancer risk is similar to earlier reports documenting a high level of interest in genetic testing for Alzheimer's disease [30] and breast cancer risk in the mid-1990s when the $B R C A 1 / 2$ mutations were discovered and prior to the widespread availability of testing for mutations in these genes [31].

To our knowledge, this study is also the first to explore the impact of test related factors, like level of risk conveyed, cost of testing and behavioral risk modifiers, on the interest in genetic testing for a common complex disease. The level of risk conveyed by the genetic test was strongly associated with interest, with a higher interest in testing in which results conveyed greater level of risk for breast cancer. Clinically, increases in risk that parallel the $75 \%$ increased scenario - the one garnering the greatest interest in the present study - might occur with genetic testing for a mutation found in the CHEK2 gene. A recurrent mutation (1100delC) in the CHEK2 gene conveys lifetime risks of $20-25 \%$ in women with a first degree relative with breast cancer [32], which translates to an approximate $75 \%$ increase over average lifetime risk. Importantly, many low-penetrance genes appear to convey smaller increases in risk, often in the range of our $25 \%$ increased-risk scenario [33], of which twothirds or more of our sample reported definite interest in the USD 150 or free scenarios. Women in the present study were not as interested in a test that informed them that their risk for breast cancer would be lower than the average risk for women their age. Perhaps lower levels of interest in genetic testing for mutations indicative of below-average risk stems from lack of a clear behavioral response to the information. When no clear behavioral response is indicated by gaining information about lower than average risk, perhaps participants felt that this test result was not useful or perhaps some of these women put more credibility in their personal and family history than in a genetic test result. We do not yet know whether genetic information related to modest changes in risk motivates behavior change for common complex diseases [34]. As such, evaluation of motivation for and specific behavioral outcomes following provision of this type of genetic information is a key target for future research [35].

In almost all scenarios, interest decreased as cost increased, similar to recent results reported by Cherkas et al. [36]. Overall, women in the present sample appear

Interest in Genetic Testing willing to pay for information about increased risk. In the most extreme cost scenarios of USD 1,500, about onefifth of our sample reported being interested in genetic testing when risk was changed by $25 \%$. As costs associated with genetic testing and entire genome scans are expected to decrease [37], such assessments will likely become more affordable for larger segments of the population. The level of interest reported in the present study is higher than the $14 \%$ uptake reported in a study offering free multiplex SNP testing [38]. This difference likely reflects the fact that this study presented idealized scenarios in order to isolate the impact of risk, cost and behavioral modifiers on interest. In contrast, participants in the study by McBride et al. [38] received extensive information about the benefits, risks and limitations of SNP testing.

The amount of money participants reported that they were willing to pay for genetic testing in these hypothetical scenarios was positively associated with cancer worry and inversely associated with understanding of test results. These results raise the possibility that women who are the most worried about cancer, yet have the poorest understanding about the risk conveyed by these tests, may be most interested in testing. This finding highlights the need to develop educational materials in order to inform individuals about the potential risks, benefits and limitations of testing. Future research can explore whether individuals who are more worried about cancer, yet potentially have less knowledge about genetic risk for cancer, may be particularly susceptible to DTC advertising for SNP testing.

A novel aspect of this study was our inclusion of risk modifiers in the scenarios. This allowed us to evaluate whether participants would be more or less interested in genetic testing if provided with a hypothetical way to modify their increased risk. To our surprise, when presented with taking a vitamin or exercising/eating a healthy diet to reduce risk, women became less interested in testing. This finding requires further exploration, particularly given recent discussion of the role of genetic information as a potential motivator to change or improve health behaviors [34, 39]. One possibility for this finding is that the women who reported decreased interest were already (or planning to begin) taking vitamins, engaging in exercise or eating a healthy diet. If this were the case, then the genetic risk information would be of little benefit to them. Whether women felt this way because they already had healthy lifestyle practices, valued behavioral more than genetic factors in disease etiology, or were already motivated to make behavior changes due to other 
factors (e.g. family history) [40] requires further exploration.

In terms of predictors of overall interest in genetic testing for modest changes in risk for breast cancer, our results are similar to other studies within the genetic testing literature. Specifically, we found that greater overall interest in testing was related to higher levels of cancer worry $[41,42]$ and greater perceived benefits of genetic testing [43], yet unrelated to the objective risk for breast cancer based on personal and family history [42]. As our sample consisted of women who had a recent negative biopsy and a family history of breast/ovarian cancer, perhaps their level of cancer worry was elevated. The timing of the study relative to the biopsy may have led to an increased level of interest and willingness to pay for testing. In addition to cancer worry, perceived benefits of genetic testing predicted overall interest in testing. These results are consistent with research describing the characteristics of 'early adopters' of BRCA1/2 testing [26]. The fact that worry and attitudes toward testing were positively related to interest in testing while objective risk and knowledge were unrelated to interest raises important questions about informed decision-making. Making fully informed decisions requires both sufficient knowledge and compatibility with a person's values [44]. Our results raise the possibility that decisions may be driven by worry and potentially unrealistic attitudes rather than knowledge and values. Thus, efforts to develop educational materials about genetic and genomic tests or other tools, such as decision aids about testing, may be warranted [45, 46]. As science progresses, we will need to know how to best educate the public about the risks, benefits and limitations of genomic tests [45] to ensure that ELSI concerns are appropriately addressed [18].

Our study had a number of strengths, including the diverse sample of women, and, because of the populationlevel applicability of genetic testing for low-penentrance genes/SNPs related to cancer risk, the focus on women at moderate to high risk of breast cancer was appropriate. In contrast to the large literature examining interest in and outcomes following genetic testing for genes that convey large increases in risk [47], this is one of the first investigations of interest in genetic testing for modest changes in breast cancer risk. Inclusion of individual and genetictest related factors as potential predictors of interest was novel. Our findings regarding the impact of behavioral risk modifiers on interest in genetic testing are intriguing, as perhaps decisions to pursue genetic/genomic tests will be predicated on the type of activities individuals would need to engage in to reduce their risk back to aver- age. Finally, given the increasing media and commercial attention to predictive genetic testing, our study of interest in testing related to small to modest changes in risk is a timely topic to examine. Further investigation into characteristics of 'early adopters' of SNP testing/personalized medicine in both controlled research settings and 'ecologically-valid' commercial settings will help explicate the psychosocial and behavioral outcomes following use of this technology and can help direct future research [38].

Results should also be interpreted in the context of the study's limitations. First, we assessed interest through hypothetical scenarios. Even though we employed strategies to make the scenarios as salient as possible [48], reported interest is only a proxy for actual uptake of testing $[38,48]$ and is almost certainly an overestimate of actual testing uptake [15]. Thus, these results should be interpreted as highlighting the association between cost, test characteristics and behavioral modifiers with interest in testing rather than focusing on the absolute level of interest conveyed. Second, we assessed broad genetic knowledge and testing attitudes using established measures that were not developed to assess issues most relevant to testing for lower-penetrance gene mutations and SNP testing (e.g. pleiotropy, potential for SNP/SNP interactions, lack of empirically demonstrated clinical utility of the information). Future research should strive to develop and employ measures that may better capture these issues. Third, we were unable to reach more than one-third of the potentially eligible sample; women who participated may have been more interested in genetics and cancer risk than the women who were unreachable. Fourth, the present sample was relatively small and consisted of women with a recent negative breast biopsy, at increased risk for breast cancer, and with potentially higher rates of cancer worry than women at average risk. Consequently, our results may overestimate interest in and willingness to pay for breast cancer genetic testing and may not be generalizable to women from the general population. Finally, although guided by the ACCE model and conducted as a largely descriptive study, we did not evaluate our results within a specific theoretical framework. Future research can begin to explore similar questions within existing theoretical frameworks used in genetic testing research $[49,50]$.

Beyond learning about individuals' interest in and understanding of genomic information, investigators are beginning to explore physicians' attitudes and knowledge of genetic susceptibility testing and genomics [51, 52]. By continuing to conduct studies that address ELSI con- 
cerns, including methods to best educate patients and providers about genomics, we will set a stronger foundation for how to appropriately translate advances in genomics into public health benefit $[18,53]$. Although the pace of scientific advances in predictive genomic tests is slower than expected [54] and debate on its overall utility exists [3,4], personalized genetic medicine will likely change the practice of medicine and may ultimately have a significant impact on improving disease prevention and control [4].

\section{Acknowledgement}

This work was supported by American Cancer Society Institutional Research Grant \#97-152-14, National Cancer Institute Grant \#K07CA131172, and The Jess and Mildred Fisher Center for Familial Cancer Research.

\section{Appendix}

Example of items used to assess interest in genetic testing for modest changes in breast cancer risk

Imagine there is a genetic test that can tell you whether you are at increased risk of getting breast cancer. This test is easily available through a cheek swab and is offered free of charge. A positive result on this test would mean that your risk for breast cancer is increased by $25 \%$. In other words, where the average woman has a lifetime breast cancer risk of $12 \%$ (about 1 in 8 ), if you tested positive with this new test, your risk would be $15 \%$ (about 1.3 in 8 ).

You would definitely $\quad$ You would probably You would probably You would definitely not have the test not have the test have the test have the test

Keeping in mind that the test would be easily obtained, free of charge, and could tell you that you were at a $25 \%$ increased risk compared to the average woman:

\begin{tabular}{|c|c|c|c|c|}
\hline a. Would you have this test? & 1 (Go to $\mathrm{D})$ & 2 & 3 & 4 \\
\hline How much would you pay for this test? & & & & \\
\hline b. Would you have this test if you had to pay USD 150 ? & 1 (Go to D) & 2 & 3 & 4 \\
\hline c. Would you have this test if you had to pay USD 1,500 ? & 1 (Go to $\mathrm{D})$ & 2 & 3 & 4 \\
\hline $\begin{array}{l}\text { D. How interested would you be in having the test if there } \\
\text { back to the average risk of } 12 \% \text { ? }\end{array}$ & idence that taking a vita & & & \\
\hline $\begin{array}{l}\text { d. Would you have this test? } \\
\text { How much would you pay for this test? }\end{array}$ & 1 (Go to $\mathrm{G})$ & 2 & 3 & 4 \\
\hline e. Would you have this test if you had to pay USD 150 ? & 1 (Go to $\mathrm{G})$ & 2 & 3 & 4 \\
\hline f. Would you have this test if you had to pay USD 1,500 ? & 1 (Go to $\mathrm{G})$ & 2 & 3 & 4 \\
\hline $\begin{array}{l}\text { G. How interested would you be in having the test if there } \\
\text { back to the average lifetime risk of } 12 \% \text { ? }\end{array}$ & vidence that exercising $r$ & 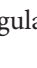 & 1) & \\
\hline $\begin{array}{l}\text { g. Would you have this test? } \\
\text { How much would you pay for this test? }\end{array}$ & 1 (Go to next section) & 2 & 3 & 4 \\
\hline h. Would you have this test if you had to pay USD 150 ? & 1 (Go to next section) & 2 & 3 & 4 \\
\hline i. Would you have this test if you had to pay USD 1,500 ? & 1 (Go to next section) & 2 & 3 & 4 \\
\hline
\end{tabular}




\section{References}

1 Burke W, Khoury MJ, Stewart A, Zimmern RL: The path from genome-based research to population health: development of an international public health genomics network. Genet Med 2006;8:451-458.

2 Guessous I, Gwinn M, Khoury MJ: Genomewide association studies in pharmacogenomics: untapped potential for translation. Genome Med 2009;1:46.

-3 Goldstein DB: Common genetic variation and human traits. N Engl J Med 2009;360: 1696-1698.

4 Hirschhorn JN: Genomewide association studies-illuminating biologic pathways. N Engl J Med 2009;360:1699-1701.

-5 Offit K: Genomic profiles for disease risk: predictive or premature? JAMA 2008;299: 1353-1355.

6 6 Ramsey S, Blough D, McDermott C, Clarke L, Bennett R, Burke W, Newcomb P: Will knowledge of gene-based colorectal cancer disease risk influence quality of life and screening behavior? Findings from a population-based study. Public Health Genomics 2010;13:1-12.

7 Gollust SE, Hull SC, Wilfond BS: Limitations of direct-to-consumer advertising for clinical genetic testing. JAMA 2002;288:17621767.

8 23andMe: Choose the DNA test that's right for you. 2010. https://www.23andme.com/.

9 deCODEme: deCODE your health. 2010. http://www.decodeme.com/.

10 Navigenics ${ }^{\circledR}$ : Clinically guided genetic analysis. 2010. http://www.navigenics.com/.

11 U.S. Government Accountability Office: Direct-to-consumer genetic tests: misleading test results are further complicated by deceptive marketing and other questionable practices. 2010. http://www.gao.gov/products/ GAO-10-847T.

12 Khoury MJ, Bradley LA: Why should genomic medicine become more evidencebased? Genomic Med 2007;1:91-93.

$\checkmark 13$ Kaye J: The regulation of direct-to-consumer genetic tests. Hum Mol Genet 2008;17:R180 R183.

- 14 Robson ME, Storm CD, Weitzel J, Wollins DS, Offit K; American Society of Clinical Oncology: American Society of Clinical Oncology policy statement update: genetic and genomic testing for cancer susceptibility. J Clin Oncol 2010;28:893-901.

-15 Sanderson SC, O’Neill SC, Bastian LA, Bepler G, McBride CM: What can interest tell us about uptake of genetic testing? Intention and behavior amongst smokers related to $\mathrm{pa}$ tients with lung cancer. Public Health Genomics 2010;13:116-124.

16 Wilde A, Meiser B, Mitchell PB, Schofield PR: Public interest in predictive genetic testing, including direct-to-consumer testing, for susceptibility to major depression: preliminary findings. Eur J Hum Genet 2010;18: 47-51.
17 Young RP, Hopkins RJ, Smith M, Hogarth DK: Smoking cessation: the potential role of risk assessment tools as motivational triggers. Postgrad Med J 2010;86:26-33.

18 Khoury MJ, Gwinn M, Yoon PW, Dowling N, Moore CA, Bradley L: The continuum of translation research in genomic medicine: how can we accelerate the appropriate integration of human genome discoveries into health care and disease prevention? Genet Med 2007;9:665-674.

19 Centers for Disease Control and Prevention: Genomic translation: ACCE model process for evaluating genetic tests. 2010. http:// www.cdc.gov/genomics/gtesting/ACCE/.

20 Haddow JE, Palomaki GE: A model process for the evaluating data on emerging genetic tests; in Khoury MJ, Little J, Burke W (eds): Human Genome Epidemiology: Scope and Strategies. New York, Oxford University Press, 2004, pp 217-233.

-21 McBride CM, Koehly LM, Sanderson SC, Kaphingst KA: The behavioral response to personalized genetic information: will genetic risk profiles motivate individuals and families to choose more healthful behaviors? Annu Rev Public Health 2010;31:89-103.

-22 Berry DA, Iversen ES Jr, Gudbjartsson DF, Hiller EH, Garber JE, Peshkin BN, Lerman C, Watson P, Lynch HT, Hilsenbeck SG, Rubinstein WS, Hughes KS, Parmigiani G: BRCAPRO validation, sensitivity of genetic testing of $B R C A 1 / B R C A 2$, and prevalence of other breast cancer susceptibility genes. J Clin Oncol 2002;20:2701-2712.

23 Southwestern Medical Center: CancerGene computer program, Version 5. 2007. http:// www 8.utsouthwestern.edu//utsw/cda/ dept47829/files/65844.html.

-24 Graves KD, Huerta E, Cullen J, Kaufman E, Sheppard V, Luta G, Isaacs C, Schwartz MD, Mandelblatt J: Perceived risk of breast cancer among Latinas attending community clinics: risk comprehension and relationship with mammography adherence. Cancer Causes Control 2008;19:1373-1382

25 Lipkus IM, Kuchibhatla M, McBride CM, Bosworth HB, Pollak KI, Siegler IC, Rimer BK: Relationships among breast cancer perceived absolute risk, comparative risk, and worries. Cancer Epidemiol Biomarkers Prev 2000;9:973-975.

26 Armstrong K, Weiner J, Weber B, Asch DA: Early adoption of $B R C A 1 / 2$ testing: who and why. Genet Med 2003;5:92-98.

- 27 Thompson HS, Valdimarsdottir HB, Duteau-Buck C, Guevarra J, Bovbjerg DH, Richmond-Avellaneda C, Amarel D, Godfrey D, Brown K, Offit K: Psychosocial predictors of BRCA counseling and testing decisions among urban African-American women. Cancer Epidemiol Biomarkers Prev 2002; 11:1579-1585.
28 Fitzmaurice GM, Laird NM, Ware JH: Applied Longitudinal Analysis. Hoboken, John Wiley \& Sons, Inc., 2004.

29 Liang KY, Zeger SL: Longitudinal data analysis using generalized linear models. Biometrika 1986;73:13-22.

30 Roberts JS, Barber M, Brown TM, Cupples LA, Farrer LA, LaRusse SA, Post SG, Quaid KA, Ravdin LD, Relkin NR, Sadovnick AD, Whitehouse PJ, Woodard JL, Green RC: Who seeks genetic susceptibility testing for Alzheimer's disease? Findings from a multisite, randomized clinical trial. Genet Med 2004;6:197-203.

-31 Andrykowski MA, Munn RK, Studts JL: Interest in learning of personal genetic risk for cancer: a general population survey. Prev Med 1996;25:527-536.

32 Narod SA: Testing for CHEK2 in the cancer genetics clinic: ready for prime time? Clin Genet 2010;78:1-7.

33 Easton DF, Pooley KA, Dunning AM, Pharoah PD, Thompson D, Ballinger DG, Struewing JP, Morrison J, Field H, Luben R, Wareham N, Ahmed S, Healey CS, Bowman R; SEARCH collaborators, Meyer KB, Haiman CA, Kolonel LK, Henderson BE, Le Marchand L, Brennan P, Sangrajrang S, Gaborieau V, Odefrey F, Shen CY, Wu PE, Wang HC, Eccles D, Evans DG, Peto J, Fletcher O, Johnson N, Seal S, Stratton MR, Rahman N, Chenevix-Trench G, Bojesen SE, Nordestgaard BG, Axelsson CK, Garcia-Closas M, Brinton L, Chanock S, Lissowska J, Peplonska B, Nevanlinna H, Fagerholm R, Eerola H, Kang D, Yoo KY, Noh DY, Ahn SH, Hunter DJ, Hankinson SE, Cox DG, Hall P, Wedren S, Liu J, Low YL, Bogdanova N, Schürmann P, Dörk T, Tollenaar RA, Jacobi CE, Devilee P, Klijn JG, Sigurdson AJ, Doody MM, Alexander BH, Zhang J, Cox A, Brock IW, MacPherson G, Reed MW, Couch FJ, Goode EL, Olson JE, Meijers-Heijboer H, van den Ouweland A, Uitterlinden A, Rivadeneira F, Milne RL, Ribas G, Gonzalez-Neira A, Benitez J, Hopper JL, McCredie M, Southey M, Giles GG, Schroen C, Justenhoven C Brauch H, Hamann U, Ko YD, Spurdle AB, Beesley J, Chen X; kConFab; AOCS Management Group, Mannermaa A, Kosma VM, Kataja V, Hartikainen J, Day NE, Cox DR, Ponder BA: Genome-wide association study identifies novel breast cancer susceptibility loci. Nature 2007;447:1087-1093.

-34 Henrikson NB, Bowen D, Burke W: Does genomic risk information motivate people to change their behavior? Genome Med 2009;1: 37.

- 35 O’Neill SC, Kaufman E, DeMarco T, Peshkin BN, McKenna K, Shelby R, Valdimarsdottir $\mathrm{H}$, Rispoli J, Schwartz MD: Changes in diet and physical activity following BRCA1/2 testing. J Psychosoc Oncol 2008;26:63-80. 
36 Cherkas LF, Harris JM, Levinson E, Spector TD, Prainsack B: A survey of UK public interest in internet-based personal genome testing. PLoS One 2010;5:e13473.

- 37 Thomas DC, Casey G, Conti DV, Haile RW, Lewinger JP, Stram DO: Methodological issues in multistage genome-wide association studies. Stat Sci 2009;24:414-429.

-38 McBride CM, Alford SH, Reid RJ, Larson EB, Baxevanis AD, Brody LC: Characteristics of users of online personalized genomic risk assessments: implications for physician-patient interactions. Genet Med 2009;11:582587.

39 Chao S, Roberts JS, Marteau TM, Silliman R, Cupples LA, Green RC: Health behavior changes after genetic risk assessment for Alzheimer disease: The REVEAL Study. Alzheimer Dis Assoc Disord 2008;22:94-97.

40 O’Neill SC, McBride CM, Alford SH, Kaphingst KS: Do behavioral risk factors and genetic causal beliefs diminish interest in seeking information about health habits? Ann Behav Med 2010;39(suppl 1):183.
41 Fraser L, Bramald S, Chapman C, Chu C, Cornelius V, Douglas F, Lucassen A, Nehammer A, Sutton S, Trivella M, Hodgson S: What motivates interest in attending a familial cancer genetics clinic? Fam Cancer 2003;2:159-168.

42 Kelly KM, Andrews JE, Case DO, Allard SL, Johnson JD: Information seeking and intentions to have genetic testing for hereditary cancers in rural and Appalachian Kentuckians. J Rural Health 2007;23:166-172.

43 Brain K, Gray J, Norman P, Parsons E, Clarke A, Rogers C, Mansel R, Harper P: Why do women attend familial breast cancer clinics? J Med Genet 2000;37:197-202.

44 Marteau TM: Communicating genetic risk information. Br Med Bull 1999;55:414-428.

45 Institute of Medicine: Implications of Genomics for Public Health. Washington, DC, National Academies, 2005. http://www.iom. edu/Reports/2005/Implications-of-Genomics-for-Public-Health-Workshop-Summary. aspx.

46 Scheuner MT, Sieverding P, Shekelle PG: Delivery of genomic medicine for common chronic adult diseases: a systematic review. JAMA 2008;299:1320-1334.

47 Halbert CH: Decisions and outcomes of genetic testing for inherited breast cancer risk. Ann Oncol 2004;15(suppl 1):i35-i39.

48 Persky S, Kaphingst KA, Condit CM, McBride CM: Assessing hypothetical scenario methodology in genetic susceptibility testing analog studies: a quantitative review. Genet Med 2007;9:727-738.
9 Baum A, Friedman AL, Zakowski SG: Stress and genetic testing for disease risk. Health Psychol 1997;16:8-19.

50 Marteau TM, Weinman J: Self-regulation and the behavioural response to DNA risk information: a theoretical analysis and framework for future research. Soc Sci Med 2006;62:1360-1368.

51 Goddard KA, Moore C, Ottman D, Szegda KL, Bradley L, Khoury MJ: Awareness and use of direct-to-consumer nutrigenomic tests, United States, 2006. Genet Med 2007;9: 510-517.

52 O'Neill SC, Luta G, Peshkin BN, Abraham A, Walker LR, Tercyak KP: Adolescent medical providers' willingness to recommend genetic susceptibility testing for nicotine addiction and lung cancer risk to adolescents. J Pediatr Psychol 2009;34:617-626.

53 Khoury MJ: Genetics and genomics in practice: the continuum from genetic disease to genetic information in health and disease. Genet Med 2003;5:261-268.

54 Schmidt C: SNPs not living up to promise; experts suggest new approach to disease ID. J Natl Cancer Inst 2007;99:188-189. 